RESEARCH PAPER

\title{
A Comparative Study of Grade 10 English Textbooks of Sindh Textbook Board and Cambridge "O Level" in the perspective of Revised Bloom's Taxonomy
}

\author{
1 Mahnoor Shaikh* $\quad 2$ Dr. Shumaila Memon
}

1. MS Scholar, English Language Development Center, Mehran, UET, Jamshoro, Sindh, Pakistan

2. Associate Professor, English Language Development Center, Mehran, UET, Jamshoro, Sindh, Pakistan

\begin{tabular}{|c|c|}
\hline PAPER INFO & ABSTRACT \\
\hline $\begin{array}{l}\text { Received: } \\
\text { July } 24,2021 \\
\text { Accepted: } \\
\text { October } 25,2021 \\
\text { Online: } \\
\text { October } 27,2021\end{array}$ & $\begin{array}{l}\text { The present study evaluated the cognitive levels of reading } \\
\text { comprehension questions present in grade } 10 \text { English Textbooks } \\
\text { namely English Textbook for grade } 10 \text { by Sindh Textbook Board and } \\
\text { compared it to Oxford Progressive English book } 10 \text { used in Cambridge } \\
\text { "O Level" in the perspective of Revised Bloom's Taxonomy. Qualitative } \\
\text { content analysis was used as a methodology to carry out the study. To }\end{array}$ \\
\hline $\begin{array}{l}\text { Keywords: } \\
\text { Bloom's Taxonomy, } \\
\text { Content Analysis } \\
\text { Reading } \\
\text { Comprehension, } \\
\text { Textbook Evaluation }\end{array}$ & $\begin{array}{l}\text { collect the data, a checklist based on Revised Bloom's taxonomy was } \\
\text { used as an instrument. A total of } 260 \text { reading comprehension } \\
\text { questions from both the textbooks were evaluated. The findings of the } \\
\text { study revealed that reading comprehension questions in English } \\
\text { textbook for grade } 10 \text { were solely based on remembering level }(100 \%)\end{array}$ \\
\hline $\begin{array}{l}\text { *Corresponding } \\
\text { Author: } \\
\text { mahnoorshaikh18 } \\
7 @ g m a i l . c o m\end{array}$ & $\begin{array}{l}\text { whereas the questions in Oxford Progressive English } 10 \text { were mainly } \\
\text { based on understanding level }(75.5 \%) \text { with a small percentage of } \\
\text { remembering }(12.5 \%) \text {, analyzing }(11.1 \%) \text { and evaluating level } \\
(0.74 \%) \text {. This suggests that the reading comprehension questions in } \\
\text { both the textbooks are dominantly based on lower-order thinking } \\
\text { skills. }\end{array}$ \\
\hline
\end{tabular}

\section{Introduction}

Textbooks play a vital role in teaching and learning process. They also serve the purpose of teaching guide and syllabus for teachers as well as a full-fledged learning source for students (Cakit, 2006). Nowadays, to meet the world's continuous changes and emphasis on critical thinking skills, nations across the world are devising ways to improve the educational quality. One way for this is to carryout textbook evaluation in order to look for the strengths and weaknesses of textbooks in use. Thus, the evaluation process covers different curriculum areas, focusing mostly on the content presented in the textbook. Overall, the process of textbook evaluation enables teachers and curriculum designers to make informed decisions, which will increase students' ability, and therefore, educational programs will become successful. In this regard, current textbooks used in any educational program should meet people's needs with relation to the modern developments of $21^{\text {st }}$ century taking place across the globe. Thus, analytical research needs to be conducted in the domain of textbook evaluation. As Riffe et al. (1998) puts that, analysis and evaluation of textbooks can provide valuable data to teachers, curriculum designers, and other 
concerned departments with valid and concrete evidence regarding the textbook's strong and weak points under the evaluative process.

Generally, English textbooks comprise of all four language skills, including reading skill, which is vital among all four skills. Textbooks consist of reading texts followed by reading comprehension questions and exercises formulated to assess the students' understanding of a particular lesson or passage. Reading comprehension questions are generally considered important vessels that can guide learners to practice all levels of critical and cognitive skills, as proposed by Bloom (1956) in his taxonomy of educational objectives. Therefore, evaluation of reading comprehension texts and questions has significant importance because to read as well as to comprehend what is being read is the essential way of gaining and developing an individual's knowledge. However, reading becomes an aimless activity when the reader does not achieve the level of understanding required to be an effective reader. Raymond (2006) believes that effective reading not only requires accurate reading skills but also that one should be able to comprehend the text easily and automatically.

Higher-order thinking skills have become pre-requisite in today's modern world. Students related to any field of education need to be proficient in critical and problemsolving skills (i-e higher-order thinking skills). It is a consensus that these skills can be taught to students from their primary level to tertiary level of education. In this regard, Franklin (1981) puts that students' higher-level thinking skills can be enhanced by answering the reading comprehension questions present in textbooks. Students can read the texts superficially on a literal level but cannot grasp the deeper meanings present in any text. Consequently, students need to be proficient in higher-order thinking skills, such as the ability to reason analytically, problem-solving, synthesis, evaluating, creating, and other higher-order mental processes through which they can become highly qualified professionals and ready to face challenges in their future endeavors (Soe \& Hlaing, 2016). Thus, questions can be an important medium to activate higher-order thinking skills in students. In this regard, Bloom (1956) believes that questions present in the textbooks should contribute to developing higher-order thinking skills without neglecting the lowerorder skills. Hence, all cognitive levels of Bloom's taxonomy should be incorporated in questions to help students engage in different thinking behaviors.

In Pakistan's context, the educational system consists of primary, secondary, higher- secondary, and tertiary level of education. In addition to this, there is a divide between the public and private sectors of education. Public-sector schools and colleges utilize the textbooks which are published and prescribed by Pakistani textbook boards. Besides this, the private sector is divided into elitist and non-elitist English medium schools. Non-elitist private schools follow textbooks that are both locally and internationally published. The elitist private schools mostly follow the textbooks written by native authors and are internationally published. Schools follow this criterion till grade 8 , later on, the choice to go either for matriculation or 0 Levels the textbooks are followed according to Pakistani textbook boards and Cambridge system of education.

In this view, the current study focuses on the comparative evaluation of two English textbooks widely taught in Sindh, Pakistan. The textbooks chosen are English Textbook for grade 10 which is prescribed by Sindh Textbook Board (STBB) taught in all BISEs of Sindh 
province, and Oxford Progressive English book 10 taught in 0 Levels in the Cambridge system. The main reason behind choosing $10^{\text {th }}$-grade textbooks is that this is the secondary level of education in Pakistan. At this stage, students need to possess higher-order thinking skills to become successful in higher-secondary and tertiary education. For this study, reading comprehension questions from both the textbooks were evaluated in the light of revised Bloom's taxonomy. Bloom's revised taxonomy is one of the major models that describe the levels of cognitive development. It mainly consists of three domains which are cognitive, psychomotor, and affective domains. In this study, the cognitive domain of revised Bloom's taxonomy is used that is two- dimensional (i-e knowledge dimension and cognitive process dimension) and consists of six cognitive levels, namely remembering, understanding, applying, analyzing, evaluating, and creating. In addition to this, to find out the gap and differences between two boards operating in a similar context, the textbooks will be compared in terms of incorporating cognitive levels of revised Bloom's taxonomy to produce students who are critical and creative thinkers.

\section{Literature Review}

Empirical research has been carried out on the use of Bloom's taxonomy in evaluating textbook questions in international and national contexts from different aspects.

A study was conducted by Ayaturrochim (2014), on the evaluation of reading tasks present in the textbook "English in Focus" under the light of Bloom's revised taxonomy. A sample consisting of 31 tasks was chosen through stratified random sampling from a population of 155 reading tasks present in 1st, $2^{\text {nd }}$ and $3^{\text {rd }}$ grade textbooks of "English in Focus". Moreover, the data for the study was gathered through a checklist. The findings showed that around $98 \%$ of the reading tasks were constructed on the remembering level, while only $2 \%$ of the tasks were formed on understanding level of revised Bloom's taxonomy.

In addition to this, Zareian et al., (2015) conducted a study in Iran on two ESP textbooks used across various universities of Iran. The study focused on exploring the levels and types of questions found in the textbooks "English for the Students of Science" (ESS) and "English for the Students of Engineering" (ESE) under the light of "cognitive domain" of Bloom's revised taxonomy. For the analysis of questions, a coding scheme was formed according to Bloom's revised taxonomy. The results showed that most of the questions in the two ESP textbooks were based on the three "lower-order thinking skills", while lowest frequency was constituted by "higher-order thinking skills". Besides this, chisquare test did not show any significant contrast between the two textbooks in terms of six cognitive levels.

Furthermore, another research was done by Ulum (2016) on the textbook "Q: Skills for success 4 Reading and Writing". The focus was to explore the degree at which the reading comprehension questions in the above textbook are based on lower as well as higher-order thinking skills. The findings demonstrated that the coursebook mainly consisted of lower-order questions that are knowledge and comprehension with $59 \%$ and $41 \%$ percentages respectively. However, higher-order questions were completely neglected in the course book. 
Similarly, Wu \& Pei (2018) carried out research on investigating the extent of critical thinking observable in the questions of 3 English language textbooks included in "intensive reading course" mainly designed for undergraduates in China. Bloom's Taxonomy was used to code and classify the after-text reading comprehension of three textbooks. The findings revealed that mostly lower- order skills are used in simple questions in the EFL textbooks, but through a gradual change higher-order questions are more prevalent in Think English. Similarly, of composite questions Think English has highest frequencies of presence of all three types of upward questions essential to critical thinking.

Furthermore, Dabbagh \& Safaei (2019) evaluated the learning objectives represented in the ELT textbooks used nationwide in the Iranian context, i-e the Prospect and Vision series which is locally published and compared them with Four Corners published by international authors. The chi-square analysis revealed that the Four Corner series dealt with LOTS and HOTS significantly more and above than Prospect and Vision series. Moreover, the results also showed that Prospect and Vision series portrayed a completely imbalanced view towards LOTS and HOTS, whereas the Four Corner series provided a balanced view. The findings of the study were significant for ELT teachers in making them aware of the cognitive levels integrated in the textbooks and recommend them to add supplementary materials when required.

In addition to this, a study was conducted by Freihat (2020), on investigation of thinking skills presented in English reading questions of Jordanian GSCE examination. A checklist formulated on Bloom's taxonomy was used as an instrument to analyze 260 reading questions. The findings revealed that the questions were mainly based on lowerorder thinking skills, namely knowledge and comprehension. The study recommended to incorporate higher-order thinking skills while writing exam papers.

In a more recent study, Tayyeh et al., (2021) analyzed the reading comprehension questions present in the textbook 'English for Iraq' for $2^{\text {nd }}$ intermediate grade based on revised Bloom's taxonomy. A mixed method content analysis was used as a method to conduct the study. A total of 282 questions were analyzed using checklist as an instrument. Findings revealed that highest frequency of questions were based on lower order thinking skills like remembering and understanding, whereas low frequency was found on questions of other four levels of the taxonomy.

In the context of Pakistan, few studies are conducted on English textbooks with their alignment to National curriculum. As, Habib \& Umar (2017), evaluated the English language textbooks that are taught in KPK at secondary level. The focus of the study was to check the alignment of English language textbooks with the learning objectives mentioned in National Curriculum Wing. Qualitative Content analysis was used, and data was collected through a checklist that focused on the four skills of English language. The findings of the study showed that English textbooks do not properly align with the objectives that are set by National Curriculum Wing of Federal Government.

Besides this, a similar kind of study was conducted on English language textbooks prescribed by Sindh Textbook Board by Gopang et al (2012). The study focused on examining the contents of English compulsory textbooks of grade IX and X against the objectives set by National Curriculum (2003). In addition to this, the study also aimed to 
investigate the impact of textbooks on schooling. The findings reported that, the contents of English language textbooks do not match the objectives set in the National Curriculum.

From the above literature review, the researcher found that several studies (Ayaturrochim, 2014; Zareian et al., 2015; Ulum, 2016; Wu \& Pei, 2018; Tayyeh et al., (2021)) have been conducted in various contexts on evaluating reading questions present in ELT textbooks under the "cognitive domain" of Bloom's taxonomy. However, in the context of Pakistan, few studies (Habib \& Umar, 2017; Gopang et al., 2012) have been conducted on ELT textbooks to evaluate the books in comparison with that of objectives set in the National Curriculum respectively. Thus, the current research study fills in the gap by comparing two ELT textbooks of grade 10th in the perspective of revised Bloom's Taxonomy in the reading comprehension questions in the context of Pakistan.

\section{Materials and Methods}

The researcher has used qualitative content analysis for the purpose of this study. Qualitative content analysis is a method which follows a systematic approach with directed technique to analyze and examine the textual content in order to decipher meanings to make sense (Forman \& Damshroder, 2007). In addition to this, Moretti et al., (2011) views qualitative content analysis as a research method in which the data is analyzed by classifying it into categories based on similar meanings.

The textbooks English Textbook Book for grade 10 and Oxford Progressive English Book 10 were chosen for this study. A total of 260 reading comprehension questions were analyzed in the light of revised Bloom's taxonomy. Furthermore, a checklist based on revised Bloom's taxonomy was used as an instrument for the study. The checklist was also added with explanatory sheets which included definitions of the cognitive levels in the cognitive process dimension of revised Bloom's taxonomy (Anderson \& Krawthwohl, 2001) along with sample questions and verbs for each cognitive level.

Besides, to analyze the data reading comprehension, questions were coded and categorized according to the six cognitive levels of revised Bloom's taxonomy. The results were then calculated and presented in the form of frequency and percentages.

\section{Results and Discussion}

English Textbook for grade 10 prescribed by STBB and Oxford Progressive English book 10 were analyzed under the cognitive process domain of Revised Bloom's Taxonomy. After coding and categorizing the reading comprehension questions, the frequency and percentages of the occurrence of each level were counted and tabulated. The following table presents the frequencies and percentages of cognitive levels present in English Textbook for grade 10 prescribed by STBB.

Table1

Frequency and Percentages for English Textbook for grade 10 by STBB

\begin{tabular}{cccc}
\hline S.R & Cognitive Levels & Frequency & Percentage \\
\hline 1 & Remembering & 125 & $100 \%$ \\
\hline 2 & Understanding & 0 & $0 \%$ \\
\hline
\end{tabular}




\begin{tabular}{lccc}
\hline 3 & Applying & 0 & $0 \%$ \\
\hline 4 & Analyzing & 0 & $0 \%$ \\
\hline 5 & Evaluating & 0 & $0 \%$ \\
\hline 6 & Creating & 0 & $0 \%$ \\
\hline & TOTAL & 125 & $100 \%$ \\
\hline
\end{tabular}

The percentages presented in the table show that all the 125 reading comprehension questions from English Textbook for grade 10 by STBB are based on the remembering level of cognitive process dimension of revised Bloom's taxonomy which is the lowest level of the taxonomy. Thus $100 \%$ of the reading comprehension questions are based on remembering, whereas $0 \%$ questions are based on understanding, applying, analyzing, evaluating, and creating level which are used for transferring of knowledge after retention of knowledge at remembering level. Although lower-order thinking skills help the learners in retention of information to be used for higher-order thinking process, but the abundance of it can make students mere spectators rather than active participants. As can be seen in the question "What was Caliph Haroon-ur-Rashid known and respected for", the students are merely asked to state or retrieve the information directly from the text without any requirement of higher-level thinking. In another instance, the question "What are the qualities of a teacher?" mainly asks the learner to list the qualities mentioned in the text. Similarly, the question "Why is fish important for us?" asks the learners the reasons for the importance of fish which can apparently come into the category of "understanding" but after the interpretation, it is clear that the question simply asks to retrieve information from the text in just one line and does not require any understanding. In another example, the question says, "What is the difference between beef and mutton?" here the sample question stem "what is the difference" usually comes in the category of understanding or analyzing as it asks for a kind of difference or comparison. But after the careful interpretation of the question and the text, it is clear that the question simply asks to retrieve the information from the text without any additional thinking from the part of the learner.

Table 2

Frequency and Percentage for Oxford Progressive English book 10

\begin{tabular}{cccc}
\hline S.R & Cognitive Levels & Frequency & Percentage \\
\hline $1:$ & Remembering & 17 & $12.5 \%$ \\
\hline 2. & Understanding & 102 & $75.5 \%$ \\
\hline $3:$ & Applying & 0 & $0 \%$ \\
\hline $4:$ & Analyzing & 15 & $11.1 \%$ \\
\hline $5:$ & Evaluating & 1 & $0.74 \%$ \\
\hline $6:$ & Creating & 0 & $0 \%$ \\
\hline & Total & 135 & $100 \%$ \\
\hline
\end{tabular}

The table shows that the textbook mainly consists of questions based on understanding level which constitutes of $75.5 \%$, whereas remembering level is relatively low with $12.5 \%$. The textbook also consists of questions based on two higher-order levels with analyzing $11.1 \%$ and evaluating $0.74 \%$. It is evident from the results that the textbook completely neglects the process of applying and creating which are essential for the process of utilizing the knowledge learned. 
This textbook mainly focuses on lower-order thinking skills in the reading comprehension questions neglecting higher-order thinking skills. Here the results will be discussed in accordance with each cognitive level from lower to higher level. The question, "Why did Humar decide to attempt the ascent even though the weather conditions were not ideal?" is categorized as remembering as the students are asked to simply recall the information from the text. Similarly, the question "Explain the American climber's concern about the insensitive media interest in climbs?" is also categorized under remembering level. Apparently, the question consists of the action verb "explain" which generally comes under "understanding" level but after the critical interpretation, it is found that the question asks to retrieve exact lines from the text. Next under discussion will be questions that come under the category of understanding level which is most dominant cognitive level found in this book. The questions like, "Explain in detail what the odds were against the rescue missions" and "Explain why the phrase 'the magic symphony' is an effective way of describing the camel's bells?" are categorized in understanding level mainly because of the use of action verb "explain" and requires understanding of the text from the part of the learner. In another instance, the question, "Find words and phrases in the text to illustrate the following attributes of the storm: a) frightening................. h) relentless" falls into understanding level because the question requires the learners to understand the whole text and then look out for words and phrases. In comparison to understanding level which is the dominant level in the textbook a smaller number of questions are also categorized under the higher-order level of analyzing. For instance, the question, "Which of the following words do you think describe the tone of this text appropriately? a) personal b) balanced c) dogmatic d) factual e) informative f) over-emotional g) one-sided. Explain your reasons for your selections" is classified under the cognitive level of analyze as it asks for the learners' personal analysis and reasons which require critical thinking. Moreover, the question, "Write a full paragraph on the following final question: The writer concludes, 'Kerry was my father's inspiration, a country of magic'. What does this mean, and how is it illustrated in the whole text?" is also categorized in analyzing level as the students need to write a complete paragraph by analyzing the given line from the text. Besides this, just one question from the textbook is based on evaluation, that is, "Do you think the writer gives a biased or an objective account of the education system in South Korea? Give full reasons with evidence from the text to support what you say." this question is based on evaluating level as it asks to make judgment about the writer's perspective and also asks for the reasons.

Qualitative content analysis of both English textbooks revealed that there are certain differences in the occurrence of cognitive levels of Revised Bloom's taxonomy in both the textbooks. The following table provides the frequencies and percentages found from both the textbooks:

Table 3

Frequencies and Percentages in English Textbook for Grade 10 By STBB and Oxford Progressive English Book 10.

\begin{tabular}{ccc}
\hline $\begin{array}{c}\text { The Cognitive Process } \\
\text { Domain }\end{array}$ & $\begin{array}{c}\text { English Textbook For } \\
\text { Grade 10 By STBB }\end{array}$ & $\begin{array}{c}\text { Oxford Progressive English } \\
\text { Book 10 }\end{array}$ \\
\hline Remembering & $100 \%(125)$ & $12.5 \%(17)$ \\
\hline Understanding & $0 \%$ & $75.5 \%(102)$ \\
\hline Applying & $0 \%$ & $0 \%$ \\
\hline
\end{tabular}




\begin{tabular}{ccc}
\hline Analyzing & $0 \%$ & $11.1 \%(15)$ \\
\hline Evaluating & $0 \%$ & $0.74 \%(1)$ \\
\hline Creating & $0 \%$ & $0 \%$ \\
\hline Total: & $100 \% \quad(125)$ & $100 \%(135)$ \\
\hline
\end{tabular}

The above table collectively presents the frequency and percentages of both textbooks. It is evident from the results that English textbook for grade 10 prescribed by STBB completely incorporates remembering level in 125 reading comprehension questions as compared to Oxford Progressive English book 10 which to some extent moves a step further and is based majorly on understanding level of revised Bloom's taxonomy.

Apart from this, in the reading comprehension questions of English Textbook for Grade 10 no other cognitive level whether lower-order or higher-order is found, whereas in Oxford Progressive English book 10 other levels apart from the dominant understanding level are found though relatively less in number (remember, analyze, evaluate). This means that former book tends to curb the thinking process of students by focusing only on retention of knowledge rather than transferring the knowledge, whereas the latter book focuses less on retention of knowledge and more on transferring the knowledge.

In another observation, the researcher found out that both the textbooks differ in the choice of the subject matter of the reading texts. The difference is also found in the complexity of the reading texts. In English textbook for grade 10 the reading texts incorporated are way too easy and does not match the standard for the students of grade 10. On the contrary, the reading texts included in Oxford Progressive English book 10 are articles and excerpts from novels that require careful interpretation to answer the reading questions following the texts. Therefore, the questions formulated in English Textbook for grade 10 are simple statements comprising of wh- questions and does not require any complex process to answer them. Whereas, in Oxford Progressive English book 10 the texts are complex therefore, the questions are formulated accordingly with wh- words and the action verbs like describe and explain. Moreover, to answer the questions even based on remembering level requires active thinking from the learners. In conclusion, reading comprehension questions present in both the textbooks does not help in developing higherorder or critical thinking skills in learners which are core requirements of $21^{\text {st }}$ century.

\section{Discussion}

The findings of the present study illustrate that lower-order thinking skills of the cognitive domain of revised Bloom's taxonomy are more frequently incorporated that the higher-order thinking skills in the reading comprehension questions present in the aforementioned English Textbooks. In English Textbook for grade 10 by STBB the dominant level is remembering, while in Oxford Progressive English Book 10 the dominant level is understanding. It is a matter of fact, that to master higher-order thinking skills, lower-order thinking skills are mandatory as Krawthwohl (2002) puts that knowledge is frequently treated as a foundation for all other educational objectives. On the other hand, the excessive use of lower-order thinking skills can make learners mere spectators rather than active participants who can think critically and creatively. Keeping this in view, at least homogenous distribution of lower and higher-order thinking skills should be there in reading comprehension questions. 
The findings of this study are in agreement with previous studies conducted by (Ayyaturrochim, 2014; Ulum, 2016; Freihat, 2020; Tayyeh et al., 2021) where lower-order thinking skills like remembering and understanding are more frequently incorporated in the reading comprehension questions in English Textbooks with less focus on higher-order thinking skills. Moreover, the findings of the current study are also in agreement with the findings of study conducted by Dabbagh \& Safaei (2019) where they evaluated and compared two textbooks one internationally published (Four Corners) and the other locally published (Prospect \& Vision Series) in the context of Iran. The findings of the study revealed that the locally published textbook deals with lower-order thinking skills more frequently than internationally published textbook. The results are similar to the findings of the current study where English Textbook for grade 10 by STBB deals only with lower-order thinking skills whereas Oxford Progressive English Book 10 also deals with two higher-order skills like analyzing and evaluating though in less in number in reading comprehension questions.

\section{Conclusion}

The current study was an attempt to evaluate reading comprehension questions of two English Textbooks namely, English Textbook for grade 10 prescribed by STBB and Oxford Progressive English 10 used in Cambridge 0 Level in the perspective of revised Bloom's taxonomy. The results elaborated that the textbooks deeply focus on the incorporation of lower-order thinking skills in the reading comprehension questions. The former textbook is solely based on remembering level which inhibits the potential of learners to think critically and perform creative tasks. Besides this, the latter textbook focuses mainly on the incorporation of understanding level which starts the process of transferring knowledge and utilizing the learned information in new situations. The attention is drawn towards the use of understanding level which is higher level than remembering but it still falls into the category of lower- order thinking skills. On the whole, these textbooks cater for a huge number of learners across Pakistan. The inability of the textbooks in developing higher-order thinking skills calls for revising the current curriculum that is widely prevalent in Sindh, Pakistan. Additionally, teachers are also required to add other materials in their teaching process along with the textbooks that will train students in becoming active participants and learners. 


\section{References}

Anderson, L. W. \& Krathwohl, D. (2001). A taxonomy for learning, teaching, and assessing: A revision of Bloom's taxonomy of educational objectives. New York: Longman.

Ayaturrochim. (2014). "The Analysis of Reading Tasks in "English in Focus" Textbook Based on Cognitive Domain of Revised Bloom's Taxonomy." (Master's Thesis), English Language Education Study Program, Education and Teachers Training Faculty, Bengkulu University

Bloom, B. S. (Ed.), (1956). Taxonomy of Educational Objectives. Handbook1: Cognitive Domain. New York: McKay.

Çakit, I. (2006). Evaluation of the EFL textbook New Bridge to Success 3 from the perspectives of students and teachers. (Unpublished master's thesis), The Middle East Technical University, Ankara, Turkey.

Dabbagh, A. \& Safaei, A. (2019). Comparative textbook evaluation: Representation of learning objectives in locally and internationally published ELT textbooks. Issues in Language Teaching, 8(1), 249-277.

Forman, J. \& Damschroder, L. (2007). Qualitative content analysis. Empirical Methods For Bioethics: A Primer, 11(1), 39-62.

Franklin, D. M. (1982). An Analysis of Questions in Sixth-grade Social Studies Textbooks Published between 1965-1965 and 1975-1979.

Freihat, N. (2020). Analyzing the Thinking Skills of the Jordanian GSCE's EFL Reading Comprehension Test Items. Journal of Education and Practice, 11(18).

Gopang, A. S. Shaikh, S. I. Parveen, S. Sangi, M. K. (2012). Critical Analysis of Textbooks of English (compulsory) of IX \& X Published by Sindh Textbook Board, Jamshoro. Pakistan. International Journal of Research in Linguistics and Social \& Applied Sciences. Vol(1).

Habib, A. \& Umar, H. (2006). A Qualitative Inquiry into the Alignment of English Textbooks with the National Curriculum at Secondary Level. NUML Journal of Critical Inquiry 15(III).

Memon, S. (2021) A Multimodal Analysis of selected Placards from the 'Aurat March' 2018 of Pakistan. Review of Applied Management and Social Sciences Vol. 4, (2) 2021, 467-478

Moretti, F. Vliet, v. L. Bensing, J. Deledda, G. Mazzi, M. Rimondini, M. Fletcher, I. (2011). A standardized approach to qualitative content analysis of focus group discussions from different countries. Patient Education and Counseling, 82(3), 420-428.

Raymond, c. (2006). Strategies for Teaching Reading Comprehension. [Online]. http://www.readingquest.org/start/graphic.html 
Riffe, D. et al,. (1998). Analyzing Media Messages: Using Quantitative Content Analysis in Research. Lawrence Erlbaum Associate.

Soe, T. \& Hlaing, N. N. (2016). Reading comprehension questions: An analysis of upper secondary English textbooks. https://pdfs.semanticscholar.org/f0ba/bd24a9df23b5974cb7679389db3ebb43f32c.p df

Syed, H. Memon, S. Chachar, Z. Zameer, S. \& Syed, T. (In press). Willingness to Communicate in a Second Language and The promise of Complex Dynamic Systems Theory: A Narrative Review. Research in Education

Tayyeh, M. N. (2021). An Analysis Of Reading Comprehension Questions In English Textbook" English For Iraq" According To Revised Bloom's Taxonomy. Turkish Journal of Computer and Mathematics Education (TURCOMAT), 12(7), 2868-2874.

Ulum, O. G. (2016). A Descriptive Content Analysis of the Extent of Bloom's Taxonomy in the Reading Comprehension Questions of the Coursebook Q: Skills for Success 4 Reading and Writing. The Qualitative Report, 21(9). Pp 1674-1683.

Wu, Y. Pei, Z. (2018). An Investigation of Critical Thinking Manifested in the Questions of EFL Textbooks for Tertiary-Level English Majors of China. American Journal of Education and Learning, 3(2): 72-84

Zareian, G. Davoudi, M. Heshmatifar, Z. \& Rahimi, J. (2015). An evaluation of questions in two ESP coursebooks based on Bloom's new taxonomy of cognitive learning domain. International Journal of Education and Research, 3(8), 313-326. 